\title{
ATIVIDADES DIDÁTICAS IMPEDIDAS E DILEMAS DE ENSINO NAS AULAS DE EdUCAÇÃO FÍSICA ${ }^{1}$
}

\author{
Prevented teaching activities and teaching dilemmas in Physical Education \\ classes
}

\section{RESUMO}

Partindo do pressuposto de que a atividade realizada pelos professores emerge de conflitos psíquicos subjacentes, esta pesquisa analisa as atividades didáticas impedidas ou suspendidas, bem como os dilemas de ensino na educação física. A pesquisa mobiliza um estudo multi-casos com quatro professores, no qual o método da autoconfrontação simples foi utilizado, baseando-se no referencial da Clínica da Atividade. As atividades suspendidas ou impedidas estão vinculadas à riscos conjunturais externos relativamente independentes do ensino como a fenômenos relacionados à interação entre o professor e os alunos. Assim, as atividades impedidas ou suspendidas são causadas por restrições de tempo ou de materiais, fatores climáticos, quantidade de alunos, mas também por eventos analisados pelos professores como falhas nos procedimentos didáticos empregados. Dois dilemas de ensino foram particularmente evidenciados: 1) oferecer tarefas atrativas ou tarefas efetivas para o aprendizado; e 2) dividir equipes de futebol mistas ou separadas por gênero. Além disso, os resultados mostram que a abordagem metodológica utilizada nesta pesquisa favorece a compreensão das atividades didáticas impedidas e dos dilemas do ensino pelos professores contribui com o desenvolvimento profissional e permite expandir o poder de agir dos docentes.

Palavras-chave: Ensino. Educação Física. Professores.

\section{ABstract}

Based on the assumption that the activity carried out by teachers emerges from underlying psychological conflicts, this research analyzes the prevented or suspended teaching activities, as well as the teaching dilemmas in physical education. The research mobilizes a multi-case study with four teachers in which the simple self-confrontation method was used, based on the reference of the Clinic of Activity. Prevented or cancelled activities are linked to external conjunctural risks relatively independent of teaching, such as phenomena related to the interaction between the teacher and the students. Thus, the activities cancelled or suspended are caused by time or material restrictions, climatic factors, number of students, but also by events analyzed by teachers as failures in the teaching procedures employed. Two teaching dilemmas were particularly evident: 1) offering attractive tasks or effective tasks for learning; and 2) divide soccer teams mixed or separated by gender. In addition, the results show that the methodological approach used in this research favor the understanding of the cancelled teaching

\footnotetext{
${ }^{1}$ Esta pesquisa teve autorização do comitê de ética da universidade sob o número 15-046-D, foi financiada pela CAPES e é um recorte dos resultados de uma pesquisa de doutorado.

2 Doutor em Ciências da Educação pela Universidade de Montreal, Mestre em Estudos da Linguagem e Licenciado em Educação Física pela Universidade Federal de Mato Grosso. Professor na Escola Municipal Madre Marta Cerutti e professor substituto no Instituto Federal de Educação, Ciência e Tecnologia de Mato Grosso, campus Cuiabá. E-mail: marcos.godoi@cba.ffmt.edu.br

${ }^{3}$ Doutora em Educação pela Pontifícia Universidade Católica do Rio de Janeiro, Mestre em Educação pela Universidade Federal de Minas Gerais, Licenciada em Educação Física pela Universidade Federal de Pelotas. Professora adjunta na Faculdade de Ciências da Educação da Universidade de Montreal, Canadá. E-mail: cecilia.borges@umontreal.ca

${ }^{4}$ Doutor em Ciências Humanas e Sociais e graduado em Educação Física pela Université de Paris Est. Maître de conférences em ergonomia no Conservatoire national des arts et métiers (CNAM), em Paris. E-mail: yannick.lemonie@cnam.fr
} 
activities and the dilemmas of teaching by teachers contributes to professional development and allows expanding the teachers power of action.

Keywords: Teaching. Physical Education. Teachers.

\section{INTRODUÇÃO}

No Brasil, até a década de 1980, o campo da didática da Educação Física foi dominado por manuais contendo diferentes formas de exercícios corporais, focalizando procedimentos e sequências didáticas, o que pode ser considerado como de suas preocupações centrais (CAPARROZ; BRACHT, 2007). No entanto, segundo esses autores, a partir da crítica ao tecnicismo na década de 1990, observa-se uma ressignificação no campo da didática da Educação Física, que passa a focalizar as características de complexidade, de imprevisibilidade e de caoticidade da prática e busca, desta forma, contribuir para a transformação das práticas pedagógicas.

Buscando um equilíbrio entre ambos, neste artigo, nos centramos na análise da atividade docente, notadamente na atividade didática. Através de procedimentos de análise das práticas, nos aproximamos não somente da realidade do trabalho docente, mas também de uma didática situada em contextos específicos. Diante das situações profissionais complexas e singulares, estes procedimentos desnudam a realidade da competência docente (PERRENOUD, 2001). Além disso, o aperfeiçoamento de qualquer atividade profissional passa pela análise do que se faz, da prática e do contraste com outras práticas (ZABALA, 1998).

O trabalho docente, convém enfatizar, é uma atividade complexa, na qual vários eventos ocorrem simultaneamente e com alto grau de incerteza (TARDIF; LESSARD, 2014; DURAND, 1996 e 2001; PERRENOUD, 2001). Embora o planejamento, tarefa importante do trabalho docente, vise a antecipação de imprevistos, quando é posto a prova no ensino, nem sempre as coisas acontecem como o previsto (DURAND, $1996 \mathrm{e}$ 2001). Isto é, entre o planejamento realizado e o planejamento antecipado, existe sempre uma distância, pois a realidade da aula é sempre mais complexa e dinâmica do que se pode antecipar.

A ergonomia do trabalho de tradição francesa tem contribuído à compreensão deste fenômeno, pondo em evidência inevitável distância entre o trabalho prescrito e o trabalho concretamente realizado pelo docente (FILLIETAZ et al., 2015), ou seja, entre o planejado e o realizado efetivamente em sala de aula. No contexto do ensino, propriamente dito, esse distanciamento entre trabalho prescrito e trabalho realizado decorre principalmente do caráter interativo do trabalho docente (TARDIF; LESSARD, 2014; DOYLE, 2006; SAUJAT, 2004; DURAND, 1996). A interatividade é uma das principais características do trabalho do professor. Nesse sentido, nos termos da sociologia do trabalho, o ensino deve ser compreendido como uma atividade de natureza interativa (TARDIF; LESSARD, 2014), ou já na linguagem didática da "teoria da ação conjunta" (AMADE-ESCOT, 2019; SENSEVY, 2011), o ensino é definido como uma atividade conjunta entre o docente e seus alunos.

Assim, Saujat (2004) explica que a aula ou o ensino em classe é uma co-construção entre o professor e os seus alunos. O primeiro é responsável por "colocar os alunos para trabalhar, gerenciando um processo de 'negociação' da tarefa no quadro de uma atividade coletiva" (p. 6). Nesse sentido, no momento do ensino, o professor é um prescritor de tarefas para alunos, mas essa prescrição deve ser negociada, porque 0 
processo de ensino-aprendizagem é considerado como uma atividade coletiva entre os atores envolvidos. Além de ser prescritor, o professor também é o ator de uma "peça" negociada com os alunos.

Se a ergonomia da atividade permitiu identificar a diferença entre a tarefa prescrita e a atividade realizada ou entre o trabalho prescrito e o trabalho efetivamente realizado pelo docente, ela limitou-se inicialmente à análise do trabalho ou da atividade dos docentes unicamente, sem tomar em conta outros aspectos. Uma visão mais completa da atividade docente exige analisar não somente a ação realizada pelo docente, mas também os conflitos subjacentes a partir dos quais emergem estas ações. A tradição decorrente da Clínica da atividade em sua tradição vygotskiana formula, assim, a ideia de que o realizado não tem o monopólio do real. O real da atividade é também o que não se faz, o que tentamos fazer sem sucesso, o que queríamos ou poderíamos fazer, o que pensamos que podemos fazer num tempo futuro (CLOT et al., 2001). Desse modo, além daquilo que é efetivamente realizado, as atividades impedidas, suspendidas, contrariadas também devem ser admitidas na análise das situações de trabalho (CLOT et al., 2000; CLOT, 2010).

A problematização da atividade docente em termos de atividade didática impedida, que consiste em descrever e analisar o ensino e a aprendizagem em sala de aula - o que é realizado e o que é impedido na atividade -, dá acesso à uma compreensão mais ampla da atividade didática dos professores e pode renovar a análise do ensino e de suas dificuldades (MONNIER; AMADE-ESCOT, 2009), bem como contribuir com o desenvolvimento profissional dos professores.

Sob esse ponto de vista, os dilemas em relação aos quais os docentes são confrontados constituem analisadores relevantes de conflitos internos, dos quais emerge a ação realizada pelo professor. Os dilemas fazem referência a uma ou mais dimensões contraditórias que ocorrem simultaneamente durante o ensino. Um dos dilemas centrais na base do ensino está relacionado à gestão e à organização coletiva das situações de ensino-aprendizagem e à gestão das aprendizagens individualmente, isto é, de cada aluno em particular; considerando as diferenças individuais de cada um e a gestão do grupo de alunos como um todo (TARDIF; LESSARD, 2014; RIA et al., 2001).

No trabalho docente os dilemas surgem diariamente; eles dividem os professores que são constantemente confrontados com múltiplas ações contraditórias. Durand (1996) descreve essas contradições em três tipos de dilemas: a) entre os diferentes objetivos educacionais, b) entre os objetivos educacionais e as condições de ensino, c) entre condições de ensino e as exigências específicas das situações de aprendizagem.

Com base nestas considerações iniciais, levantamos as seguintes perguntas de pesquisa: o que ocasiona as atividades impedidas relatadas pelos professores nas aulas de educação física? São decorrentes de dilemas de ensino? Com quais dilemas de ensino os professores são confrontados? Em decorrência, o objetivo deste estudo é descrever e analisar as atividades impedidas ou contrariadas, bem como os dilemas de ensino nas aulas de educação física, levando em consideração a perspectiva dos docentes.

A pertinência de se estudar as atividades docentes impedidas no campo da educação física, decorre entre outros, dos escassos os estudos sobre esta temática na área. A maioria das pesquisas focaliza os dilemas dos professores de educação física iniciantes (GARIGLIO; REIS, 2016; KRUG; KRUG; ILHA, 2013; RIA et al, 2001). Há ainda o estudo de Coral e Lleixá (2014) sobre os dilemas surgidos durante a implementação de um novo 
modelo de ensino. Sobre as atividades didáticas impedidas, um dos raros estudos é a pesquisa de Monnier e Amade-Escot (2009) realizada em escolas consideradas de meio social difícil.

\section{A Clínica da Atividade e escolhas metodológicas}

Esta pesquisa apoia-se no quadro teórico da Clínica da Atividade, que considera que as transformações no trabalho só são duráveis quando realizadas pelos próprios trabalhadores. Esta abordagem busca intervir nas situações de trabalho, favorecendo transformações na atividade e restabelecendo o poder de agir dos trabalhadores (VIEIRA; FAIITA, 2003). Assim, a análise do trabalho pelos profissionais funciona como "um instrumento do desenvolvimento da consciência do sujeito quando lhe é oferecida a possibilidade de alterar o estatuto do vivido: de objeto de análise, o vivido pode tornar-se meio para se viver outras vidas" (CLOT, 2010, p. 223).

$\mathrm{Na}$ tradição da ergonomia da atividade de língua francesa e na Clínica da atividade, certos autores mostraram a necessidade de uma abordagem dialógica para apreender o real da atividade (CLOT; FAÏTA, 2000). Dentre os métodos de pesquisa e intervenção nas situações de trabalho desenvolvidos pela Clínica da atividade estão a autoconfrontação simples e cruzada (GODOI; BENITES; BORGES, 2019; CLOT, 2010; LÉMONIE; ROBIN, 2010; VIEIRA; FAÏTA, 2003) e a instrução ao sósia (CLOT, 2010; LÉMONIE; ROBIN, 2010).

Os métodos de pesquisa utilizados pela Clínica da atividade se apoiam no diálogo entre os trabalhadores sobre as situações de trabalho. Vale notar que para Bakhtin (1997), a interação verbal realizada por meio das enunciações constitui a verdadeira substância da língua presente em todas as relações entre indivíduos, inclusive na relação comunicacional de interação entre professor e alunos nas aulas.

Na perspectiva bakhtiniana, o enunciador sempre leva em conta a percepção do seu discurso pelo destinatário: suas concepções, convicções, preconceitos, simpatias e antipatias, pois tudo isto determinará a sua compreensão responsiva. O interlocutor, ao perceber e compreender o significado do discurso do outro, ocupa simultaneamente uma posição responsiva ativa: concorda ou discorda (total ou parcialmente), completa-o, aplica-o, prepara-se para usá-lo etc. (BAKHTIN, 2003).

Por sua vez, as situações de análise do trabalho criadas pelas Clínica da atividade favorecem o desenvolvimento dos trabalhadores. Do ponto de vista psicológico vygotskiano o indivíduo se torna sujeito quando faz, sozinho e de outro modo, o que já havia experimentado com os outros, ao encontrar-se com eles numa zona de desenvolvimento potencial. Ele reconstrói para si de outro modo o que havia produzido e o que produziu com os outros, quando considera "o outro gesto possível, o outro objeto, a outra palavra, a outra ideia, a outra atividade, a outra possibilidade não ainda alcançada" (CLOT, 2010, p. 210). Esta perspectiva é coerente com a nossa postura epistemológica que valoriza a experiência concreta de trabalho dos docentes (o que eles sabem e fazem no seu trabalho) e, também, a linguagem como forma de expressão do raciocínio (o que expressam sobre o trabalho), numa perspectiva dialógica. 
Este é um estudo de tipo qualitativo, descritivo e multi-casos (YIN, 2015). Os participantes do estudo foram quatro professores, com diferentes tempos de experiência profissional e suas turmas mistas do $4^{\circ}$ e do $6^{\circ}$ ano do Ensino Fundamental, que atuavam em escolas em diferentes regiões da cidade. $O$ quadro a seguir mostra as características dos professores colaboradores da pesquisa e de seus contextos de ensino.

Quadro 1- Características dos colaboradores da pesquisa

\begin{tabular}{|c|c|c|c|c|}
\hline & Escola A & \multicolumn{2}{|l|}{ Escola B } & Escola C \\
\hline Professores & Safira & Ametista & Esmeralda & Diamante \\
\hline $\begin{array}{c}\text { Sexo e } \\
\text { Idade }\end{array}$ & $\begin{array}{c}\text { Mulher, } \\
39 \text { anos }\end{array}$ & $\begin{array}{c}\text { Mulher, } \\
33 \text { anos }\end{array}$ & $\begin{array}{c}\text { Mulher, } \\
42 \text { anos }\end{array}$ & $\begin{array}{c}\text { Homem, } \\
41 \text { anos }\end{array}$ \\
\hline $\begin{array}{c}\text { Tempo na } \\
\text { escola }\end{array}$ & 2 anos & 2 anos & 15 anos & 15 anos \\
\hline $\begin{array}{c}\text { Turma } \\
\text { observada }\end{array}$ & $4^{\circ}$ ano & $4^{\circ}$ ano & $6^{\circ}$ ano & $6^{\circ}$ ano \\
\hline № alunos & 28 & 18 & 26 & 28 \\
\hline $\begin{array}{c}\text { Frequência e } \\
\text { duração das } \\
\text { aulas }\end{array}$ & $\begin{array}{c}1 \times \text { por semana } \\
2 \text { horas }\end{array}$ & \multicolumn{2}{|c|}{$\begin{array}{c}\text { 1x por semana } \\
2 \text { horas }\end{array}$} & $\begin{array}{c}2 \times \text { por semana } \\
45 \text { minutos }\end{array}$ \\
\hline
\end{tabular}

Fonte: dados da pesquisa de campo.

Nas escolas 1 e 2 as aulas são geminadas ou duplas. Isso devido a uma recomendação da Secretaria Municipal de Educação para que as escolas pudessem concentrar a hora atividade (planejamento, correção dos trabalhos dos alunos) dos professores em um único dia. A escola 3 não adotou esta diretiva e manteve as aulas de 45 minutos, duas vezes por semana. Todos os professores e os pais das crianças, indiretamente envolvidas na observação das aulas, assinaram o termo de consentimento livre e esclarecido. Além disso, esta pesquisa teve autorização do comitê de ética da universidade sob o número 15046-D.

As aulas foram observadas e filmadas (um total de 44 horas de filmagem) durante dois meses. Os professores assistiram os vídeos das aulas e se analisaram através do método da autoconfrontação simples e cruzada (CLOT, 2010; VIEIRA; FAÏTA, 2003). Segundo Clot (2010), na autoconfrontação os participantes são expostos à imagem do próprio trabalho e colocam em palavras o que eles julgam ser suas constantes ou regularidades. Eles dialogam com o outro e com eles mesmos ao verbalizarem as condutas que eles observam. Esta análise do sujeito sobre ele mesmo privilegia a reformulação e a avaliação da sua própria ação. A autoconfrontação é dita simples quando envolve o pesquisador e o sujeito da pesquisa, é cruzada quando envolve um outro par ou mais, os quais visualizam mutualmente as imagens das suas aulas em presença do pesquisador. Este último age como mediador, relançando os participantes, reorientando o foco da reflexão sobre aspectos não explícitos da atividade etc.

O material coletado através dos vídeos das aulas e das suas respectivas sessões de autoconfrontação simples e cruzada foi transcrito e organizado em episódios de ensino. Os turnos de fala (Tf) dos professores receberam números 
de acordo com ordem de fala no diálogo, por exemplo: Tf 1 (turno de fala 1). Em seguida, procedeu-se à análise temática continuada (PAILLÉ; MUCCHIELLI, 2012) do corpus. Neste tipo de análise, identificam-se as unidades de significação, ou seja, uma frase ou conjunto de frases ligadas à uma mesma ideia ou tema no texto. As categorias de análise podem ser conceituais, baseadas na literatura ou emergente da leitura do corpus.

Neste artigo, focalizam-se somente as categorias conceituais relacionadas às atividades impedidas, suspendidas ou contrariadas e aos dilemas de ensino, em especial: às razões de agir dos professores; à intenção de mudança futura e à criação de novas metas; à orientação e análise da atividade voltada para o trabalho do professor ou dos alunos.

Os resultados aqui apresentados são um recorte de uma pesquisa mais ampla que analisou um total de 60 episódios de ensino dos quatro professores colaboradores. Porém, neste artigo são apresentados: 1) somente os resultados oriundos da autoconfrontação simples, pois nem todas as aulas passaram por sessões de autoconfrontação cruzada; 2) e seis episódios de ensino nos quais identificou-se atividades didáticas impedidas, suspendidas ou contrariadas, bem como dilemas de ensino da educação física.

\section{ANÁLISE E DISCUSSÃO DOS EPISÓdIOS DE ENSINO}

Inicialmente, vale ressaltar que algumas atividades foram suspendidas, impedidas ou contrariadas em decorrência de imprevistos contextuais externos relativamente independentes ao ensino e aos professores, tais como: a restrições de tempo ou materiais, a influência de fatores climáticos, ao número insuficiente de participantes para realizar a atividade planejada. Por exemplo: "A peteca era para ter sido feita na aula passada, mas nós não fizemos porque choveu. Então nós vamos fazer hoje" (Ametista, aula 3); "Pessoal, hoje a gente ia fazer o jogo de taco, mas uma turma estava jogando antes e os tacos quebraram" (Ametista, aula 5).

Houve também atividades impedidas ou suspendidas relacionadas a interação entre o professor e os alunos, como períodos de desatenção e comportamento perturbador por parte dos alunos, em que os professores devem esperar pelo silêncio para continuar a explicação. Por exemplo: "M., por favor! Vamos colaborar? Olha o tanto de tempo que a gente leva para se organizar, para vocês ouvirem o que eu estou falando?" (Esmeralda, aula 6). Em outras ocasiões, as atividades podem ser suspendidas devido a gestão do tempo da aula, por exemplo: "Esta aula teve a questão que tinha extrapolado o tempo, a outra turma estava esperando. Então a gente não teve tempo para fazer os comentários finais. Mostrou eu dispensando eles para a outra aula que eu teria com o $8^{\circ}$ ano. Por isto que não teve a roda de conversa final." (Diamante, aula 6).

A esse respeito, pesquisas anteriores (RUFINO, 2017; KRUG, KRUG; ILHA, 2013; BOSSLE; MOLINA NETO, 2009; WITTIZORECKI; MOLINA NETO, 2005) destacaram certas restrições que os professores de educação física enfrentam em suas aulas e que na nossa perspectiva podem causar certos impedimentos e desvios na atividade de ensino, por exemplo: problemas de infraestrutura e de materiais; elevado número de alunos nas turmas, grupos mistos e heterogêneos, 
falta de interesse dos alunos pelas atividades propostas, indisciplina de alunos e conflitos nas aulas, fatores climáticos, reunião de mais de uma turma em um só grupo para cobrir os professores ausentes da escola. No entanto, face a estes problemas, os professores desenvolvem estratégias e saberes para lidar com essas restrições (WITTIZORECKI; MOLINA NETO, 2005).

Em outros episódios de ensino, foram identificadas atividades impedidas, suspendidas ou contrariadas devido à falhas nos procedimentos didáticos dos professores, tal como no primeiro episódio de ensino apresentado no quadro 1 a seguir, no qual Safira é confrontada com uma atividade contrariada durante $o$ jogo de campo minado, sendo que depois da autoconfrontação ela vislumbra mudar as regras de pontuação do jogo.

Quadro 2- Episódio de ensino da Safira: atividade contrariada

\begin{tabular}{|c|c|}
\hline \multicolumn{2}{|c|}{ Aula 4: jogo do campo minado, $4^{\circ}$ ano, 20 alunos } \\
\hline Episódio em aula & Autoconfrontação simples (ACS) \\
\hline $\begin{array}{l}\text { Safira monta o circuito de arcos } \\
\text { na quadra para o jogo de campo minado, } \\
\text { divide os alunos em duas equipes A e B } \\
\text { e os posiciona em duas filas. } \\
\text { Os alunos devem realizar o } \\
\text { percurso saltando nos arcos escolhidos } \\
\text { por eles, mas evitando as "bombas". } \\
\text { O participante que salta em um } \\
\text { arco minado, deve retornar para o final } \\
\text { da fila da sua equipe. } \\
\text { Durante a prática nenhum aluno } \\
\text { conseguiu realizar o percurso até o final } \\
\text { e nenhuma equipe marcou pontos. Safira } \\
\text { mudou o roteiro de bombas várias vezes. }\end{array}$ & $\begin{array}{l}\text { Tf } 16 \text { Safira: É, também, eu fui mudando } \\
\text { muito. Eu falei que eu ia mudar só quando eles } \\
\text { terminassem. Só que aí quando estourou a } \\
\text { bomba eu falei: 'Eles já vão saber'. Daí eu ia } \\
\text { mudando. } \\
\text { Tf } 20 \text { Safira: Eu nunca tinha aplicado esta } \\
\text { atividade do campo minado desta forma. Eu } \\
\text { achei ela bem interessante e que os alunos iriam } \\
\text { gostar, mas eu segui a risca, pontuando só } \\
\text { quando concluíssem. } \\
\text { Tf } 27 \text { Pesquisador: Você mudaria algo } \\
\text { nesta aula? } \\
\text { Tf } 28 \text { Safira: Então, esta pontuação para } \\
\text { fazer a atividade ficar mais divertida. Às vezes a } \\
\text { competição faz com que a aula fique mais } \\
\text { dinâmica, mais prazerosa para eles, né? E } \\
\text { somando os pontos, a atividade não ia deixar de } \\
\text { ser cooperativa, eles iam estar competindo, mas } \\
\text { nas equipes. }\end{array}$ \\
\hline
\end{tabular}

Fonte: informações da pesquisa de campo.

Durante a autoconfrontação simples, no turno de fala 16, Safira nota que ela mudou muito o percurso de bombas, sua razão de agir decorre da pressuposição da professora de que os alunos adivinhariam facilmente o percurso correto, daí resolveu mudar com maior frequência os percursos.

No turno de fala 20, Safira acrescenta que foi a primeira vez que ela fez essa prática, ou seja, se tratava de uma novidade para a turma e para ela. Ademais, esta foi uma atividade realizada de forma contrariada, pois nenhum aluno chegou ao final da prática, as equipes não marcaram pontos. 
No turno de fala 28, Safira expressa sua intenção de mudança, especialmente no sistema de pontuação. Desse modo, a experiência da atividade contrariada e a visualização do vídeo permitiram que a professora refletisse sobre sua atividade e ampliasse seu poder de agir, visualizando novas possibilidades de condução desse jogo.

No caso desta pesquisa, Safira constatou que um dos procedimentos que ela utilizou na aula impediu que os alunos concluíssem a tarefa com sucesso. Segundo o estudo de Oliveira e Daolio (2014), o engajamento ou a resistência dos alunos às atividades propostas pode se dar devido ao desinteresse em relação à atividade proposta (conteúdo) ou em relação à forma em que ele é desenvolvido (método).

Vale notar que em todas as aulas observadas da Safira, ela segue uma mesma estrutura. Primeiro, faz uma parte prática na quadra e depois leva seus alunos para a sala de aula, onde passa matéria no quadro e explica, faz o balanço final da aula e a chamada. No episódio de ensino seguinte, no quadro 2, ficou evidenciado um dilema de ensino na aula da Safira, durante a realização da avaliação da aula, o qual tem repercussão na rotina de trabalho da professora.

Quadro 3- Episódio de ensino da Safira: dilema entre pedir que os alunos desenhem ou escrevam o que mais gostaram na aula e por quê?

\begin{tabular}{|c|c|}
\hline \multicolumn{2}{|c|}{ Aula 3: jogos cooperativos, $4^{\circ}$ ano, 25 alunos } \\
\hline Episódio em aula & Autoconfrontação simples (ACS) \\
\hline 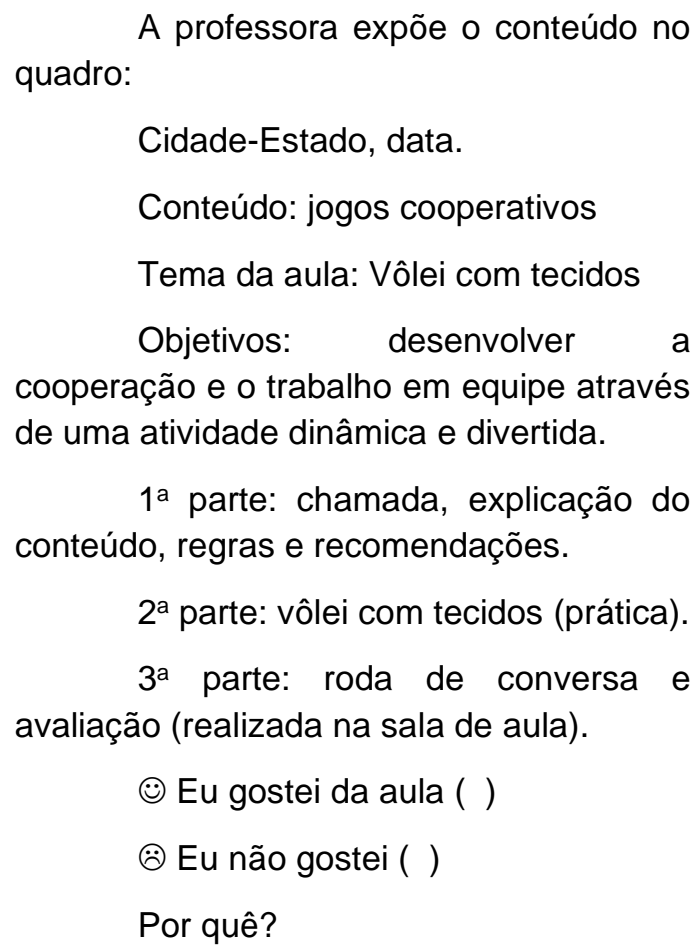 & $\begin{array}{l}19 \text { Safira: É, eles têm uma resistência } \\
\text { para colocar no papel porque gostaram da } \\
\text { aula e eu queria que eles escrevessem, se } \\
\text { eles gostaram ou não gostaram e por quê. } \\
\text { Mas eles preferem desenhar e eles se } \\
\text { expressam melhor assim. Teoricamente era } \\
\text { para eles já estarem alfabetizados, têm alguns } \\
\text { que estão avançados, só que outros que têm } \\
\text { dificuldade de escrever. [...]. Eu acho uma } \\
\text { ferramenta importante, mesmo que eles não } \\
\text { coloquem muitas coisas, mas a gente tem } \\
\text { uma noção do que ele achou da aula. } \\
\quad 20 \text { Pesquisador: Por quê você passa } \\
\text { matéria no quadro? } \\
\quad 21 \text { Safira: [...], porque no quadro eles } \\
\text { vão conseguir entender como se fosse um } \\
\text { mapa da aula. Ele vai conseguir entender em } \\
\text { que parte ele vai fazer tal coisa. E entender } \\
\text { que a aula tem uma sequência. }\end{array}$ \\
\hline
\end{tabular}

Fonte: informações da pesquisa de campo.

No turno de fala 19, Safira explica sua razão de agir em fazer uma avaliação da aula de forma escrita, quando ela demanda que os alunos escrevam o porquê gostaram ou não da aula. Sua razão de agir é fazer com que seus alunos expressem suas opiniões sobre a aula. No entanto, há um dilema de ensino, pois 
seus alunos preferem desenhar do que escrever e alguns deles ainda têm dificuldades na escrita.

Ela permite então que eles desenhem, mas não deixa de expor o conteúdo no quadro para eles copiarem. No turno de fala 21, Safira explica sua razão de agir, seu objetivo é que os seus alunos saibam como agir em cada momento e compreendam melhor a sequência da aula, ou seja, a ação desta professora está acoplada à atividade de seus alunos nas aulas. A orientação da atividade da professora neste momento está voltada para a busca da eficiência dos alunos e para a melhor compreensão do conteúdo e da dinâmica da aula. Sem tê-lo manifestado durante a autoconfrontação, o fato de fazer os alunos copiarem a matéria pode ter também um impacto na apropriação da escrita pelos alunos.

Este dilema de ensino - propor práticas atraentes vs. práticas efetivas para aprendizagem - também foi encontrado na pesquisa de Coral e Lleixà (2014). No que tange ao processo de utilização de textos nas aulas de educação física, tal como no caso da Safira que passava matéria no quadro, a pesquisa de Vieira, Freire e Rodrigues (2015), constatou que os alunos têm uma resistência inicial, mas que o prolongamento da utilização dessa estratégia de ensino diminui a resistência dos alunos. Ademais, na avaliação dos alunos nas aulas de educação física, os professores têm utilizado registros iconográficos (fotografias, desenhos), mas também textuais (diários da educação física) e orais (entrevistas) com os alunos (SANTOS et al. 2014).

No episódio 3, primeiramente a Ametista aborda confecção da peteca e o jogo de peteca num segundo momento. Esta atividade foi uma realizada em conjunto com um outra turma de alunos, da Esmeralda. Em sala de aula, Ametista explica e demonstra como construir a peteca. Depois, ela leva os alunos para o estacionamento para pegar areia e em seguida se dirigem para o pátio da escola onde terminam a construção da peteca nas mesas. Lá eles encontraram a outra turma, da Esmeralda.

Quadro 4- Episódio de ensino da Ametista: atividade suspendida

\begin{tabular}{|c|c|}
\hline \multicolumn{2}{|c|}{ Aula 3: jogo de peteca, $4^{\circ}$ ano, 17 alunos } \\
\hline Episódio em aula & Autoconfrontação simples \\
\hline $\begin{array}{l}\text { Durante a confecção da peteca, } \\
\text { alguns alunos realizam a tarefa sozinhos, } \\
\text { outros esperam pela ajuda da Ametista ou } \\
\text { organizam-se em pequenos grupos. A turma } \\
\text { da Esmeralda chega atrasada para confecção } \\
\text { da peteca o que ocasiona uma certa } \\
\text { desorganização do grupo. Uma vez que as } \\
\text { petecas ficam prontas, os alunos começam a } \\
\text { jogar em duplas, sem a supervisão da } \\
\text { professora, pois esta estava ocupada } \\
\text { ajudando outros alunos a terminarem suas } \\
\text { petecas. }\end{array}$ & $\begin{array}{l}\text { Tf } 8 \text { Ametista: Eu acho que se a aula } \\
\text { fosse só com a minha turma renderia mais, } \\
\text { mas era uma aula conjunta, [...]. } \\
\text { Tf } 21 \text { Ametista: Eu acho que eu teria } \\
\text { mais atenção dos alunos, a todo momento, } \\
\text { aí, eu estou preocupada com a turma da } \\
\text { Esmeralda. A gente tinha que estar } \\
\text { construindo a peteca juntos, mas a turma } \\
\text { dela chegou atrasada. Já tinha vários alunos } \\
\text { meus com a peteca pronta, então aí não dá } \\
\text { para você segurar as crianças. Então não } \\
\text { deu para fazer uma sequência, fazer os } \\
\text { movimentos certos, aprofundar mais. }\end{array}$ \\
\hline
\end{tabular}

Fonte: informações da pesquisa de campo. 
No turno de fala 8, Ametista faz uma apreciação da aula. Segundo ela, a aula seria mais produtiva se estivesse unicamente com a sua turma. Em seguida, no turno de fala 21, Ametista explica que a turma da Esmeralda chegou atrasada e que vários dos seus alunos já haviam terminado a confecção das petecas. Assim, ocorreu um descompasso entre a tarefa de confecção da peteca e a de realização dos educativos subsequentes de manipulação do objeto em duplas. Enquanto uns haviam terminado, outros ainda estavam construindo suas petecas. À medida que terminavam, os primeiros, já iam sendo postos em duplas para executar os movimentos, sem a supervisão da professora, que estava ocupada com os segundos.

Enfim, para ela, foi impossível controlar o grupo e fazer uma sequência de exercícios educativos naquele momento como planejado. Desse modo, os exercícios com peteca foram cancelados e esta foi uma atividade suspendida. Na sequência, Ametista levou os alunos para a quadra de vôlei e organizou um jogo de peteca entre duas equipes. Bem que a causa da suspensão da atividade tenha sido o atraso da turma da Esmeralda, o fato é que isto causou um descompasso na sequência das atividades planejadas.

Estes resultados são indicadores do desenvolvimento potencial dos professores e congruentes com o que é relatado por Monnier e Amade-Escot (2009). As autoras destacam que a ação do professor persegue um horizonte distante que vai além da própria ação, ou seja, por mais que as atividades didáticas impedidas ou suspendidas aconteçam em determinas aulas, ao longo do tempo, os professores podem retomá-las e transformá-las no seu ensino futuro.

O episódio de ensino do quadro 4 a seguir, diz respeito a uma aula da Esmeralda onde o tema era dança e expressão corporal. No início da aula, ela fez uma retrospectiva da lição anterior. $O$ quadro a seguir mostra uma sequência das atividades propostas e realizadas ou impedidas na aula da Esmeralda. 
Quadro 5 - Episódio de ensino da Esmeralda: atividade impedida, intenção de mudanças e engajamento corporal da professora

\begin{tabular}{|c|c|}
\hline \multicolumn{2}{|c|}{ Aula 4: dança e expressão corporal, $6^{\circ}$ ano, 21 alunos } \\
\hline Episódio em aula & Autoconfrontação simples \\
\hline $\begin{array}{l}\text { Esmeralda diz aos alunos que eles } \\
\text { devem ouvir a música primeiro, que o mais } \\
\text { importante não é só o ritmo, mas também a letra. } \\
\text { Ela coloca a música e organiza a atividade ao } \\
\text { mesmo tempo: } \\
\text { Esmeralda: Se quiser movimentar, pode } \\
\text { movimentar. A cabeça, ombro, se quiser bater o } \\
\text { pé no chão. É um ritmo que agradou vocês? } \\
\text { Gostaram? } \\
\text { Depois, ela propõe outra prática, os } \\
\text { alunos devem atravessar a sala em duplas, } \\
\text { dançando no ritmo da música. Ela chamou um } \\
\text { menino para começar a prática com ela, em } \\
\text { dupla. } \\
\text { Esmeralda: Quem eu chamar vai ter que } \\
\text { vir! W., vem! } \\
\text { Porém, o menino não quis participar, } \\
\text { Esmeralda insistiu um pouco, mas ele estava } \\
\text { tímido. } \\
\text { Então ela passou para o próximo } \\
\text { exercício chamando todos os alunos para o } \\
\text { centro da sala. } \\
\text { Esmeralda: Vamos, vamos! Nós vamos } \\
\text { fazer uma atividade que é o seguinte, vocês vão } \\
\text { andar pela sala e eu vou falar: "Mão direita!" Você } \\
\text { vai ter que bater a mão direita na mão direita de } \\
\text { alguém. Eu vou falar: "Mão direita, mão } \\
\text { esquerda!" Aí você vai bater a mão direita e a } \\
\text { mão esquerda! [demonstra]. Eu vou colocar a } \\
\text { música aqui! E aí eu vou aumentando a } \\
\text { sequência de movimentos, tá bom? Não pode } \\
\text { ficar ninguém sem fazer! Tudo bem? } \\
\text { Esmeralda participa da prática com os } \\
\text { alunos e convida os que estavam apenas } \\
\text { observando para participar da prática. }\end{array}$ & $\begin{array}{l}\text { Tf } 18 \text { Esmeralda: Talvez assim, } \\
\text { se eles já estivessem em círculo, mas de } \\
\text { pé, talvez participariam com mais } \\
\text { facilidade. Eles iam sentir mais a música. } \\
\text { Inclusive a hora que eu falei: "Se } \\
\text { quiserem movimentar a cabeça, bater o } \\
\text { pé no chão!" Eu pensei: "Aí, eles estão } \\
\text { sentados!" Então isto foi um ponto falho, } \\
\text { eles estarem ouvindo a música, mas } \\
\text { sentados e a mesa os protege e serve } \\
\text { como barreira. Eu não tinha percebido. } \\
\text { Tf } 19 \text { Esmeralda: Eu gosto de } \\
\text { fazer junto com eles, de chamar eles } \\
\text { para fazer. Eu acho que às vezes eles } \\
\text { não se sentem muito envolvidos com o } \\
\text { estilo da música, se bem que não dá para } \\
\text { agradar a todos! [...], eu procuro } \\
\text { participar e entrar um pouco no universo } \\
\text { deles, porque se eu falar para fazer e não } \\
\text { fizer junto, né? É uma forma de envolvê- } \\
\text { los. } \\
\text { Tf } 73 \text { Esmeralda: É, eu mudaria } \\
\text { naquele momento da dança, trazer os } \\
\text { alunos para a frente das mesas, até } \\
\text { mesmo para romper aquela barreira para } \\
\text { se movimentar. [...]. }\end{array}$ \\
\hline
\end{tabular}

Fonte: informações da pesquisa de campo.

No turno de fala 18, Esmeralda considera novas possibilidades para fazer esta prática, com os alunos em círculo, de pé. Além disso, ela também aborda a contradição entre suas instruções para que eles se movimentassem e o fato de que eles estavam sentados, verbalizando sua linguagem interior, ou seu pensamento durante a aula: "Aí, eles estão sentados". Na segunda prática, 
identificamos uma atividade impedida ou contrariada porque o aluno se recusou a participar.

Ademais, nesta aula, observamos o engajamento corporal da professora na prática com seus alunos. Ela dá as instruções, mas também participa da prática. No ensino de dança, o professor é como um espelho para os alunos, o que caracteriza o uso da linguagem corporal como um instrumento da atividade docente. No turno de fala 19, Esmeralda faz uma apreciação de que gosta de participar com eles e de encorajá-los a praticar. Além disso, notamos um dilema no ensino, utilizar músicas escolhidas pelos alunos, mas estas músicas nem sempre agradam a todos. Portanto, Esmeralda quer estabelecer uma abordagem mais democrática ao propor aos alunos. No entanto, em sua reflexão durante a autoconfrontação, ela percebeu que não é fácil agradar a todos.

No turno de fala 73, Esmeralda manifestou sua intenção de mudança, de convidar todos os alunos para o centro da sala para se movimentarem mais livremente. $\mathrm{O}$ que demonstra a criação de novas metas para a professora e sua intenção de mudança, o que permite ampliar seu poder de agir. Tal como no episódio anterior, este resultado é um indicador do desenvolvimento potencial dos professores. Segundo Clot (2008), o desenvolvimento potencial dos trabalhadores acontece quando consideram "o outro gesto possível, o outro objeto, a outra ideia, a outra atividade, a outra possibilidade ainda não realizada", ou seja, olhando para o próprio trabalho, os trabalhadores são expostos à descoberta.

O episódio seguinte destaca a dificuldade da Esmeralda para colocar seus alunos em ação durante a aula de dança e expressão corporal. 
Quadro 6 - Episódio de ensino da Esmeralda: dilema de ensino oferecer tarefas atrativas ou tarefas efetivas para o aprendizado dos alunos

\begin{tabular}{|c|c|}
\hline \multicolumn{2}{|c|}{ Aula 4: dança e expressão corporal, $6^{\circ}$ ano, 21 alunos } \\
\hline Episódio em aula & Autoconfrontação simples \\
\hline $\begin{array}{l}\text { Esmeralda faz uma atividade de } \\
\text { prática de ritmo. Os alunos estão em } \\
\text { círculo, de mãos dadas. Eles devem } \\
\text { bater o pé direito para frente e para trás, } \\
\text { sincronizados. } \\
\text { Esta prática se assemelha a uma } \\
\text { dança indígena em um círculo. Sempre } \\
\text { que o grupo bate um pé no chão, cada } \\
\text { um deve dizer a vogal de seu primeiro } \\
\text { nome. Os alunos estavam participando } \\
\text { sem motivação e sem ritmo. Esmeralda } \\
\text { para a prática e diz: } \\
\text { Esmeralda: } \\
\text { atenção! Vocês vão falar as vogais a } \\
\text { hora que bate o pé no chão! Tá bom? } \\
\text { Bateu o pé no chão e fala: “l, a, o, u" Sei } \\
\text { lá! De acordo com o nome de vocês! } \\
\text { Então vamos lá! Vamos fazer assim, } \\
\text { como todos já sabem o nome de todo } \\
\text { mundo, então a gente vai falar o nome } \\
\text { daquele colega, junto com o colega, } \\
\text { pode ser? [...]. } \\
\text { A maior parte do grupo participa, } \\
\text { mas quatro meninas estavam só } \\
\text { observando. }\end{array}$ & $\begin{array}{l}\text { Tf } 31 \text { Esmeralda: Pois é, eu fico triste } \\
\text { quando o aluno não participa porque dá a } \\
\text { impressão/ é porque a atividade não está } \\
\text { correspondendo muito as expectativas deles. } \\
\text { Mas ao mesmo tempo eu não posso entrar muito } \\
\text { nesta "neura", porque nem sempre eles gostam! } \\
\text { Enfim, assim, tem gente que gosta de português, } \\
\text { tem gente que gosta de matemática, ou não gosta } \\
\text { de geografia, mas tem que estudar. Então, ao } \\
\text { mesmo tempo que eu respeito eles por não } \\
\text { gostarem de fazer, eu também fico assim meio } \\
\text { chateada por não estar correspondendo às } \\
\text { expectativas deles." } \\
\text { Tf } 32 \text { Pesquisador: Do que será que } \\
\text { essas meninas gostam? } \\
\text { Tf } 33 \text { Esmeralda: Elas gostam de funk! } \\
\text { Se colocar um funk ali elas vão dançar! E às } \\
\text { vezes, elas estão num universo tão, me desculpe } \\
\text { o termo, tão fútil né? Que impede de permitir } \\
\text { outros conhecimentos. Então elas ficam meio } \\
\text { resistentes. Agora mesmo elas estão envolvidas } \\
\text { com a apresentação de sertanejo para a festa } \\
\text { junina. A M. [aluna], a L. [aluna], a S. [aluna], } \\
\text { destas quatro que estão aí, três estão } \\
\text { participando. Mas assim, já está mais no contexto } \\
\text { delas, né? Realmente, esta atividade é } \\
\text { monótona, mas eu preciso que eles trabalhem o } \\
\text { ritmo, né? Então, na aula anterior a gente fez a } \\
\text { atividade do "tabôbô", neste dia a gente fez a } \\
\text { atividade de ritmo com as vogais dos nomes. } \\
\text { Então tem turma que aceita bem, tem turma que } \\
\text { não aceita. }\end{array}$ \\
\hline
\end{tabular}

Fonte: informações da pesquisa.

Como dito anteriormente, a aula é uma co-construção entre o professor e os alunos. No entanto, existem situações em que alguns alunos podem se recusar a participar, como neste quinto episódio. No turno de fala 31, Esmeralda expressa seu sentimento de tristeza quando os alunos não participam das práticas. Isto parece ser um indicador de auto-afetação da professora nesta situação de trabalho. Ela cogita que a prática proposta por ela não atendeu as expectativas dos seus alunos. Constatamos aqui um dilema de ensino quando ela respeita o direito dos alunos de não gostar de algumas práticas, mas por outro lado, afirma que é preciso que os alunos estudem todas as disciplinas e conteúdos escolares. 
No turno de fala 33, Esmeralda argumenta que nesta situação ela precisava trabalhar o ritmo e concluiu que existem grupos mais ou menos receptivos. Além disso, ela reconhece que as meninas que se recusaram a participar gostam mais de funk e se ela estivesse usando este estilo elas dançariam. Além disso, Esmeralda informou que estas meninas estavam envolvidas em uma apresentação de sertanejo que ocorreria na festa junina. Deste modo, nota-se que essas meninas participam de atividades de dança, mas se recusaram a participar da atividade proposta pela professora.

Aqui existe outro dilema de ensino, entre ofertar tarefas atrativas para os alunos ou tarefas efetivas que produzem um efeito esperado, no caso desta situação, o desenvolvimento das habilidades de ritmo. Vale notar que Esmeralda abordou dança numa sequência de quatro aulas, nas duas últimas os alunos e alunas estavam mais participativos e engajados na proposta pedagógica e nas atividades propostas por ela.

Por sua vez, as pesquisas de Gariglio e Reis (2016) e Krug, Krug e Illha (2013) evidenciaram que um dos dilemas dos professores iniciantes em educação física é convencer os alunos a participar das aulas. Para isso, é preciso implicar os alunos não tanto por mecanismo de coerção, mas por canais de comunicação e interação capazes de persuadi-los da ação docente pela motivação, pela empatia dos alunos em relação aos professores ou ainda pela habilidade de tornar os conteúdos mais atraentes aos olhos dos alunos (GARIGLIO; REIS, 2016).

A respeito da participação dos alunos nas aulas de dança no caso da Esmeralda, a pesquisa de Salomão e Sebben (2016) constatou que nas aulas de educação física com uma turma do $6^{\circ}$ ano do Ensino Fundamental, os alunos dançavam se queriam e que apenas pequenos grupos dançavam ou se dispunham a aprender. Porém, alguns estilos de música empolgaram mais os alunos como 0 Funk, o Eletrônico, o Sertanejo, o Pop, o Hip-Hop e o Rap.

Vale notar ainda que nas aulas de dança, conseguir construir uma relação de confiança com os alunos para que eles se sintam confortáveis para se expressar corporalmente sem julgamentos dos colegas não é uma tarefa simples. Segundo Montaud e Amade-Escot (2014), sempre há o risco de o aluno dançar de maneira desajeitada e ser ridicularizado pelos seus pares, ou ainda, alguns alunos podem brincar e se fazer de palhaço ou não ousar a dançar.

O último episódio de ensino aborda uma sequência da aula de futsal da Esmeralda. Algumas vezes ela realiza partidas de futsal com seus alunos na última parte das aulas. Os alunos solicitavam seguidamente esta prática que, segundo a professora ocorre de forma mais recreativa, sem visar um objetivo de aprendizagem propriamente dito. 
Quadro 7 - Episódio de ensino da Esmeralda: dilema de ensino de organizar equipes mistas ou separadas por gênero no jogo de futsal

\begin{tabular}{|c|c|}
\hline \multicolumn{2}{|c|}{ Aula 3: esporte/futsal. $6^{\circ}$ ano, 26 alunos } \\
\hline Episódio em aula & Autoconfrontação simples \\
\hline $\begin{array}{l}\text { Esmeralda: Deu certo este jogo misto de vocês? } \\
\text { Alunos: Nãoooo!!! } \\
\text { Esmeralda: O quê não deu certo? } \\
\text { S. [menina]: Os meninos não sabem jogar! Eles } \\
\text { quebram [machucam] a gente! } \\
\text { Aluno: Mentira, fica quieta! Mentira! } \\
\text { Esmeralda: Espera aí! Aconteceram algumas } \\
\text { faltas, algumas ocorrências que eu quero que vocês } \\
\text { reflitam se vale a pena ficar assim! Tem gente que fica } \\
\text { discutindo durante o jogo para provocar o colega, fica } \\
\text { empurrando! Vocês acham que isto é correto? Não é! } \\
\text { Vocês gostariam que o colega fizesse assim com vocês? } \\
\text { Uma menina começa a discutir com o C. E. } \\
\text { [menino]. } \\
\text { Esmeralda: Tá, então nós vamos fazer o seguinte... } \\
\text { [Dois alunos estão discutindo]. ... na próxima aula nos } \\
\text { vamos fazer o seguinte. Eu que vou dividir os times, tá } \\
\text { bom? Não vai ter três alunos que vão escolher, eu que vou } \\
\text { distribuir os times. Combinado? [...]. E vamos pensar se o } \\
\text { time misto está dando certo! Eu acho que o time misto vai } \\
\text { ter que ficar mais para frente, porque vocês ficam } \\
\text { discutindo muito. Nós vamos fazer dois times de menina, } \\
\text { dois times de menino. Quando vocês alcançarem uma } \\
\text { maturidade para jogar misto, aí a gente joga. }\end{array}$ & $\begin{array}{l}\text { Tf } 41 \text { Esmeralda: [...]. } \\
\text { Eu resolvi fazer isto daí [jogo } \\
\text { com equipes mistas] para ver } \\
\text { se eles conseguiam interagir, } \\
\text { diminuir estas diferenças, mas } \\
\text { não deu muito certo. [...], eu } \\
\text { lembro assim que uma ou } \\
\text { outra aluna ficou discutindo } \\
\text { [...]. E os meninos não gostam } \\
\text { muito disto. E às vezes eles } \\
\text { fazem alguma falta, ou alguma } \\
\text { coisa sem graça e perturba as } \\
\text { meninas. Mas eu acho que não } \\
\text { foi uma coisa do outro mundo! } \\
\text { Eu fiz estes comentários para } \\
\text { que isto não piorasse. }\end{array}$ \\
\hline
\end{tabular}

Fonte: informações da pesquisa.

No turno de fala 41, Esmeralda explica a sua razão de agir em relação ao jogo de futsal misto, sua intenção era a de que os meninos e meninas integrassem. No entanto, Esmeralda julga a prática do jogo com equipes mistas, fazendo uma apreciação de que "não deu muito certo". Observamos também um dilema de ensino entre fazer jogos com equipes mistas ou separadas por gênero. Diante dos conflitos e faltas surgidas no momento do jogo, Esmeralda busca resolver o dilema provisoriamente dizendo para seus alunos que nas próximas aulas ela faria equipes divididas por gênero, ou seja, ela cria novas metas para o seu trabalho futuro.

Segundo Ria et al. (2001), diante dos dilemas de ensino, os professores fazem suas escolhas provisórias concentrando-se temporariamente apenas na alternativa considerada prioritária, sendo que a outra é abandonada momentaneamente. No entanto, essa escolha está longe de ser satisfatória. Evitar conflitos entre os alunos criando equipes mistas é uma escolha satisfatória 
no contexto de foco no conteúdo; no entanto, envolve retirar o ensino de suas virtudes educacionais de uma perspectiva de co-educação.

Nesse sentido, Saraiva (2005) e Gomes, Silva e Queiróz (2000) explicam que as aulas mistas e as aulas na perspectiva da coeducação não têm o mesmo significado. Segundo essas autoras, nas aulas mistas há apenas uma distribuição e organização de meninas e meninos em conjunto no espaço escolar. As aulas de coeducação implicam a problematização das relações entre os gêneros, com o objetivo de compreender a construção cultural das diferentes posições de poder ocupadas por mulheres e homens em nossa sociedade, além de tentar minimizar as relações hierárquicas entre os gêneros.

\section{Considerações finaIS}

Nesta pesquisa, identificamos atividades impedidas, suspendidas e realizadas de maneira contrariada, além de dilemas de ensino nas aulas dos professores de educação física. As primeiras são causadas por restrições de tempo ou materiais, fatores climáticos, quantidade (elevada ou baixa) de alunos nas aulas, mas também por eventos analisados pelos professores como falhas nos procedimentos didáticos utilizados nas aulas. Dois dilemas de ensino foram mais destacados: oferecer tarefas atraentes ou tarefas efetivas de aprendizado para os alunos; organizar equipes de futsal mistas ou não mistas. Diante desses dilemas, as professoras fizeram escolhas temporárias e não totalmente satisfatórias.

Diante dos conflitos relatados pelos professores, a reflexividade dos professores mobilizada pelo método da autoconfrontação possibilitou a verbalização de intenções de mudanças nos procedimentos didáticos dos professores, o que possibilita a expansão do seu poder de agir e contribui para o desenvolvimento profissional docente. As intenções de mudança expressas pelos professores foram: mudar o sistema de pontos do jogo do campo minado (Ametista); convidar todos os alunos para o centro da sala, para que possam se movimentar mais livremente na aula de dança (Esmeralda); jogar o jogo peteca com apenas uma turma de alunos ao invés de duas turmas (Ametista).

Em nossa análise, identificamos alguns dilemas que os professores enfrentaram no ensino. Por exemplo: os alunos da Safira gostam de desenhar e têm dificuldade em escrever. Assim, ela alterna a tarefa de pedir aos alunos para escrever o porquê eles gostaram ou não das aulas, mas pede também que eles façam desenhos que expressem suas apreciações. Esmeralda trabalhou práticas de ritmo, mas algumas meninas não se engajaram na prática, pois gostavam mais das danças Funk e Sertanejo. Esmeralda respeita o direito dos alunos de nem sempre gostarem das práticas ou das músicas propostas, mas quando a aula não corresponde às expectativas dos alunos ela se incomodava. Sendo assim, as duas professoras enfrentaram o dilema entre oferecer práticas de interesse dos alunos ou que contribuam para a aprendizagem efetiva, de acordo com as perspectivas dos professores.

A compreensão das atividades didáticas impedidas, suspendidas ou contrariadas e dos dilemas do ensino contribui com o desenvolvimento profissional dos professores, uma vez que permite expandir o poder de agir dos 
docentes, visualizar novas alternativas e possibilidades de ação para tornar o ensino mais assertivo, efetivo e significativo. Esse não é um desafio individual, mas de todos aqueles que buscam uma educação física de qualidade. Deste modo, esperamos que os resultados desta pesquisa possam contribuir para a formação inicial e continuada dos professores de educação física comprometidos com um ensino e com a aprendizagem dos alunos com qualidade e eficácia.

Enfim, é importante destacar que compreendemos o desenvolvimento profissional dos professores, incluindo aqui as atividades didáticas do processo de ensino-aprendizagem, como um processo inacabado. Durante toda a vida profissional os professores vão aprender com os alunos, com sua experiência, com a análise da própria prática, com as trocas de experiências formais ou informais. Os dilemas de ensino e as atividades impedidas estarão presentes nesse processo de desenvolvimento profissional, mas quanto mais recursos analíticos o professor tiver à disposição, mais facilmente encontrará saídas, alternativas e caminhos viáveis em seu trabalho didático-pedagógico.

\section{REFERÊNCIAS}

AMADE-ESCOT, Chantal. Épistémologies pratiques et action didactique conjointe du professeur et des élèves. Éducation et didactique, v. 13, n. 1, p. 109-114, 2019.

BAKHTIN, Mikhail. Marxismo e Filosofia da Linguagem: problemas fundamentais do método sociológico na ciência da linguagem. 8. ed. São Paulo: Hucitec, 1997.

BAKHTIN, Mikhail. Estética da criação verbal. 4. ed. São Paulo: Martins Fontes, 2003.

BOSSLE, Fabiano; MOLINA NETO, Vicente. No "olho do furacão": uma autoetnografia em uma escola da rede municipal de ensino de Porto Alegre. Revista Brasileira de Ciências do Esporte, Campinas, v. 31, n. 1, p. 131-146, set. 2009.

CAPARROZ, Francisco Eduardo; BRACHT, Valter. O tempo e o lugar de uma didática da educação física. Revista Brasileira de Ciências do Esporte, v. 28, n. 2, p. 21-37, 2007.

CLOT, Yves. Trabalho e poder de agir. Belo Horizonte: Fabrefactum, 2010.

CLOT, Yves et al. Entretiens en autoconfrontation croisée: une méthode en clinique de l'activité. Pistes, v. 2, n. 1, p. 1-7, 2001.

CORAL, Josep; LLEIXÀ, Teresa. La enseñanza de la Educación Física mediante el enfoque educativo Clil: la resolución de los dilemas surgidos durante un proceso de investigación-acción. Movimento, Porto Alegre, v. 20, n. 4, p. 1447-1472, out./dez. 2014.

DOYLE, Walter. Ecological Approaches to Classroom Management. In: EVERTSON, Carolyn; WEINSTEIN, Carol S. (Org.). Handbook of classroom management. New York/London: Routledge/Lawrence Erbaulm, 2006, p. 97-126.

DURAND, Marc. L'enseignement en milieu scolaire. Paris: PUF, 1996.

DURAND, Marc. Chronomètre et sous-vêtement. Paris: EPS, 2001.

FILLIETAZ, Laurent et al. Conceptualizing and connecting francophone perspectives on learning through and for work. In: FILLIETAZ, Laurent; BILLETT, Stephen. (Org.). Francophone perspectives of learning through work. Conceptions, traditions and Practices. London: Springer, 2015, p. 19-48.

GARIGLIO, José Ângelo; REIS, Carolina Guimarães. Dilemas e aprendizagens profissionais de professores iniciantes de educação física. Diálogo Educacional, Curitiba, v. 16, n. 50, p. 911936, out./dez. 2016.

GODOI, Marcos; BENITES, Larissa Cerignoni; BORGES, Cecilia. O uso da autoconfrontação 
simples e cruzada para analisar o ensino de educação física. Movimento, Porto Alegre, v. 25, e25071, 2019.

GOMES, Paula; SILVA, Paula; QUEIROZ, Paula. Equidade na educação. Educação Física e Desporto na Escola. Portugal: Associação Portuguesa A Mulher e o Desporto, 2000.

LÉMONIE, Yannick; ROBIN, Jean-François. Clinique de l'activité et recherche pour l'intervention en ÉPS et en Sport. In: MUSARD, Mathilde; LOQUET, Monique; CARLIER, Ghislain (Org.). Sciences de l'intervention en ÉPS et en sport: résultats de recherche et fondements théoriques. Paris: EPS, 2010. p. 87-106.

MONTAUD, Dominique; AMADE-ESCOT, Chantal. Le rapport aux œuvres en danse au collège : contrainte et autonomie du curriculum. Le cas de la monstration de la proposition dansée. Questions Vives, n. 22, p. 1-20, 2014.

MONNIER, Nathalie; AMADE-ESCOT, Chantal. L'activité didactique empêchée: outil d'intelligibilité de la pratique enseignante en milieu difficile. Revue française de pédagogie, $v$. 168, p. 59-73, 2009.

OLIVEIRA, Rogério Cruz; DAOLIO, Jocimar. Educação Física, prática pedagógica e nãodiretividade: a produção de uma "periferia da quadra". Educação em Revista, Belo Horizonte, v. 30, n. 2, p. 71-94, abr./jun. 2014.

PAILLÉ, Pierre; MUCCHIELLI, Alex. L'analyse qualitative en sciences humaines et sociales. Paris: Armand Colin, 2012.

PERRENOUD, Philippe. Ensinar: agir na urgência, decidir na incerteza. $2^{a}$ ed. Porto Alegre: ArtMed, 2001.

RIA, Luc et al. Les dilemmes des enseignants débutants: Études lors des premières expériences de classe en éducation physique. Sciences et Motricité, n. 42, p. 47-58, 2001.

RUFINO, Luiz Gustavo Bontatto. O trabalho docente na perspectiva de professores de educação física: análise de alguns fatores condicionantes e suas restrições para o desenvolvimento da prática pedagógica. Movimento, Porto Alegre, v. 23, n. 4, p. 1257-1270, out./dez. 2017.

SALOMÃO, Alexandre França; SEBBEN, Thiago Felipe. Experimentações culturalmente orientadas: um relato de artistagens sobre a dança na escola. In: Congresso Sul-Brasileiro de Ciências do Esporte, 8, 2016, Criciúma-SC. [Anais...] Criciúma: Colégio Brasileiro de Ciências do Esporte, 2016, p. 1-21. Disponível em: http://congressos.cbce.org.br/index.php/8csbce/2016sul/schedConf/presentations. Acesso em: 07 set. 2021.

SANTOS, Wagner dos et al. Avaliação na educação física escolar: construindo possibilidades para a atuação profissional. Educação em Revista, Belo Horizonte, v. 30, n. 4, p. 153-179, out./dez. 2014.

SARAIVA, Maria do Carmo. Co-educação física e esportes: quando a diferença é mito. 2. ed. ljuí: Ed. Unijuí, 2005.

SAUJAT, Frédéric. Spécificités de l'activité d'enseignants débutants et "genres de l'activité professorale ». Polifonia, Cuiabá, v. 8, n. 4, p. 1-26, 2004.

SENSEVY Gérard. Le sens du savoir. Éléments pour une théorie de l'action conjointe en didactique. Bruxelles: De Boeck, 2011.

TARDIF, Maurice; LESSARD, Claude. O trabalho docente: elementos para uma teoria da docência como profissão de interações humanas. 9 ed. Petrópolis-RJ: Vozes, 2014.

VIEIRA, Pollyane de Barros Albuquerque; FREIRE, Elisabete dos Santos; RODRIGUES, Gracieli Massoli. O texto escrito como recurso didático nas aulas de educação física. Movimento, Porto Alegre, v. 21, n. 4, p. 929-944, out./dez. 2015.

VIEIRA, Marcos; FAïTA, Daniel. Quando os outros olham outros de si mesmo: reflexões metodológicas sobre a autoconfrontação cruzada. Polifonia, Cuiabá, v. 7, p. 27-65, 2003.

WITTIZORECKI, Elisandro S.; MOLINA NETO, Vicente. O trabalho docente dos professores de educação física na Rede Municipal de Ensino de Porto Alegre. Movimento, Porto Alegre, v. 11, n. 1, p. 47-70, jan./abr. 2005. 
YIN, Robert K. Estudo de caso: planejamento e métodos. 5ª ed. Porto Alegre (RS): Bookman, 2015.

ZABALA, Antoni. A prática educativa: como ensinar. Porto Alegre: ArtMed, 1998.

Data da submissão: 02/07/2021

Data da aprovação: 19/09/2020 